\title{
KOMUNIKASI INTERPERSONAL DAN FASILITAS KESEHATAN SERTA PENGARUHNYA TERHADAP KEPERCAYAAN DAN WOMPADA RUMAH SAKIT UMUM DAERAH KOTA MATARAM
}

\author{
Nurul Indah Wijayanti \\ Handry Sudiartha Athar
}

\begin{abstract}
This research examined the influence of interpersonal communication, medical facilities, trust and word of mouth (WOM) outpatients in Mataram City Hospital. Specifically, the objectives of this research was to determine the significance effect of the interpersonal communication and medical facilities toward the trust and WOM outpatients in Mataram City Hospital. The samples using purposive sampling method. Respondents were public patients undergoing outpatient treatment and patients who had more than two times in poly Mataram City Hospital. This research uses the path analysis with the application Statistical Product and Service Solutions (SPSS). The results showed that interpersonal communication positive and significant effect toward the trust, medical facilities positive and significant effect toward the trust, interpersonal communication positive and significant effect toward WOM, medical facilities are not exhibited significantly positive effect toward WOM, trust were positive and significant effect toward WOM, interpersonal communication positive and significant effect toward WOM through trust, as well as medical facilities significant and positive effect toward WOM through trust outpatients in Mataram City Hospital.
\end{abstract}

Keywords: Interpersonal Communication, Medical Facilities, Trust, and Word Of Mouth (WOM).

\section{Pendahuluan}

Tingkat pemanfaatan fasilitas rumah sakit di Indonesia hingga saat ini nampaknya masih belum optimal. Di bidang hospitality masih terdapat kesenjangan antara kebutuhan dan permintaan terhadap pelayanan kesehatan. Penduduk yang berobat jalan dengan menggunakan fasilitas rumah sakit hanya 7,10 persen. Jumlah ini masih jauh di bawah Puskesmas dan Puskesmas Pembantu yang mencapai angka 33,40 persen maupun dokter praktek yang mencapai 27,50 persen. Dibandingkan negara-negara tetangga, jumlah tempat tidur rumah sakit di Indonesia relatif masih rendah, yaitu 60 tempat tidur RS per 100.000 penduduk, atau ke-8 paling rendah di dunia dalam rasio tempat tidur dibandingkan jumlah penduduk. Angka ini di Indonesia hampir relatif tidak berubah sejak 10 tahun terakhir. Walaupun pasokan tempat tidur rumah sakit masih sangat rendah, ternyata pemakaian tempat tidur juga masih rendah. Bed occupancy rate (BOR) hanya sekitar 55-57 persen selama 10 tahun terakhir. Rata-rata tiap hari dari 100.000 penduduk hanya 30 orang yang sedang dirawat di rumah sakit. Data tersebut menunjukkan bahwa kebutuhan yang tinggi ini tidak diiringi dengan permintaan yang tinggi (Djojodibroto, 2001).

Banyaknya bermunculan pelayanan kesehatan non-medis yang tidak diketahui ternyata diserbu juga oleh masyarakat awam, misalnya pengobatan 
alternatif dukun dan sebagainya. Ini adalah indikasi adanya fenomena menurunnya minat orang sakit untuk memeriksakan dirinya ke dokter. Fenomena tersebut mungkin dipengaruhi oleh tingginya biaya kesehatan maupun berkurangnya kepercayaan masyarakat pada pelayanan seorang tenaga kesehatan. Salah satu masalah yang sering menimbulkan ketidakpuasan pasien adalah komunikasi antara dokter dan atau petugas kesehatan dengan pasien dan keluarganya. Lemahnya komunikasi antar petugas kesehatan dapat mempengaruhi kualitas pelayanan kedokteran yang diberikan, yang pada gilirannya dapat menimbulkan kerugian pada pasien dan keluarganya. Sebagian dokter merasa tidak mempunyai waktu yang cukup untuk berbincang-bincang dengan pasiennya. Akibatnya, dokter bisa saja tidak mendapatkan keterangan yang cukup untuk menegakkan diagnosis dan menentukan perencanaan dan tindakan lebih lanjut. Dari sisi pasien, umumnya pasien merasa dalam posisi lebih rendah di hadapan dokter.

Tidak mudah bagi dokter untuk menggali keterangan dari pasien. Perlu dibangun hubungan saling percaya yang dilandasi keterbukaan dan pengertian akan kebutuhan, harapan, maupun kepentingan masing-masing. Terbangunnya hubungan saling percaya, pasien akan memberikan keterangan yang benar dan lengkap sehingga dapat membantu dokter dalam mendiagnosis penyakit pasien secara baik dan memberi obat yang tepat bagi pasien. Komunikasi yang baik dan berlangsung dalam kedudukan setara (sederajat) sangat diperlukan agar pasien mau menceritakan sakit atau keluhan yang dialaminya secara jujur dan jelas. Komunikasi efektif mampu mempengaruhi emosi pasien dalam pengambilan keputusan tentang rencana tindakan selanjutnya, sedangkan komunikasi tidak efektif akan mengundang masalah.

Rumah Sakit Umum Daerah Kota Mataram (RSUD Kota Mataram) merupakan rumah sakit kelas B yang dimiliki oleh Pemerintah Kota Mataram dimana berbentuk badan layanan umum daerah. Sebagai badan layanan umum daerah, Rumah Sakit Umum Daerah Kota Mataram dituntut untuk dapat menyelenggarakan praktek bisnis yang sehat dan memiliki kemandirian dalam pengelolaan keuangan. Rumah Sakit Umum Daerah Kota Mataram harus dapat menutupi biaya operasionalnya agar tetap eksis. Berdasarkan data kunjungan pasien dan penerimaan pasien rata-rata pada bulan Januari sampai Desember 2014, terjadi fluktuasi. Namun pada dasarnya memang terlihat bahwa terdapat peningkatan jumlah pasien pada bulan April, Agustus, dan Oktober 2014. Data kunjungan pasien menunjukkan terjadi kecenderungan penurunan jumlah pasien yang berobat selama tahun 2014, dengan rata-rata penurunan sebesar 1,67 persen untuk setiap bulannya. Penurunan jumlah kunjungan ini bukan berarti kesehatan masyarakat kota Mataram meningkat. Kemungkinan besar penurunan jumlah kunjungan dikarenakan banyaknya rumah sakit swasta dan dokter praktek yang bermunculan di kota Mataram. Untuk itu perlu dilakukan evaluasi dari sisi pelanggannya dan mengetahui kepercayaan setiap pasien terhadap RSUD Kota Mataram. Keseluruhan ini tentunya dapat mempengaruhi kepercayaan terhadap rumah sakit yang selanjutnya dapat mempengaruhi loyalitas dalam melakukan rekomendasi WOM positif kepada orang lain mengenai rumah sakit. 
Beberapa informasi yang didapatkan dari survey pendahuluan yaitu banyak pasien yang berobat ke RSUD Kota Mataram merasa kurang diberi tanggapan dan perhatian secara penuh oleh dokter yang menanganinya, terlebih untuk pasien yang memiliki penyakit yang lebih serius. Hal ini dikarenakan jumlah pasien yang ditangani oleh masing-masing dokter sangat banyak, sehingga komunikasi pada saat mendiagnosis pasien belum secara penuh diterima dan dimengerti oleh para pasien. Tentu saja komunikasi interpersonal antara dokter dengan pasiennya dirasakan kurang efektif. Terkait dengan fasilitas kesehatan yang disediakan oleh pihak RSUD Kota Mataram diperoleh informasi dari pasien rawat jalan pada beberapa poli masih ada peralatan kesehatan yang belum tersedia secara penuh untuk menunjang proses pengobatan yang dirasa akan menghambat kesembuhan dari pasien itu sendiri, hal tersebut menimbulkan keraguan dibenak pasien yang berobat sehingga mereka harus berfikir kembali untuk menjalani pengobatan pada rumah sakit lain yang memiliki fasilitas kesehatan yang lengkap sesuai dengan kebutuhannya.

Berdasarkan masalah di atas maka rumusan masalah yang diajukan dalam penelitian ini adalah apakah komunikasi interpersonal dan fasilitas kesehatanberpengaruh signifikan terhadap WOM melalui kepercayaan pasien pada Rumah Sakit Umum Daerah Kota Mataram?

\section{Tinjauan Teoridan Rumusan Hipotesis}

Hubungan Komunikasi Interpersonal dan Fasilitas Kesehatan dengan Kepercayaan

Komunikasi interpersonal dan fasilitas kesehatan merupakan inti kelangsungan hidup sebuah lembaga kesehatan seperti rumah sakit. Gerakan revolusi komunikasi melalui pendekatan manajemen komunikasi terpadu menjadi tuntutan yang tidak boleh diabaikan jika suatu lembaga kesehatan ingin hidup dan berkembang. Persaingan yang semakin ketat akhir-akhir ini menuntut sebuah lembaga penyedia jasa/layanan kesehatan untuk selalu memanjakan pasien dengan memberikan komunikasi interpersonal dan fasilitas kesehatan yang terbaik. Para pasien akan mencari produk layanan kesehatan dari rumah sakit yang dapat memberikan komunikasi interpersonal dan fasilitas kesehatan yang terbaik kepadanya (Assauri, 2003).

Parasuraman et al (1985) menjelaskan bahwa komunikasi interpersonal dan fasilitas kesehatan ini berpengaruh pada kepercayaan pasien. Jika pasien memperoleh komunikasi interpersonal dan fasilitas kesehatan melebihi harapannya maka pasien akan mengatakan rumah sakit tersebut berkualitas dan kemudian berkembang menjadi kepercayaan terhadap penyedia jasa kesehatan tersebut dan sebaliknya apabila pasien merasa komunikasi interpersonal dan fasilitas kesehatan yang diberikan tidak sesuai dengan harapan maka pasien akan mengatakan komunikasi interpersonal dan fasilitas kesehatan tersebut tidak berkualitas sehingga nantinya akan mempengaruhi kepercayaan pasien. 
Rumah sakit harus memberikan komunikasi interpersonal dan fasilitas kesehatan yang memanjakan pasiennya karena jika pasien merasa nyaman dengan komunikasi interpersonal dan fasilitas kesehatan yang diberikan perusahaan akan dapat menciptakan hubungan yang kuat dan menguntungkan rumah sakit. Hubungan antara komunikasi interpersonal dan fasilitas kesehatan dan kepercayaan secara luas di dokumentasikan dalam literatur pemasaran, hubungan tersebut secara teoritis maupun empiris adalah positif seperti yang telah diteliti oleh Alif dan Harahap (2013).

Secara teoritis ketika komunikasi interpersonal dan fasilitas kesehatan yang diberikan mampu memenuhi atau melampaui pengharapan atau ekspektasi pasien maka pasien tersebut akan menjadi semakin percaya lagi terhadap penyedia jasa kesehatan (Parasuraman et al., 1985). Secara empiris banyak penelitian dengan latar belakang sampel yang berbeda-beda telah membuktikan bahwa komunikasi interpersonal dan fasilitas kesehatan mempunyai pengaruh positif terhadap kepercayaan pasien seperti yang diungkapkan oleh Bendapudi dan Berry (1997). Morgan dan Hunt (1994) juga mengungkapkan hal serupa yakni komunikasi interpersonal dan fasilitas kesehatan memiliki dampak positif bagi kepercayaan pasien. Rumah sakit harus meningkatkan komunikasi interpersonal dan fasilitas kesehatannya pada pasien, dimana semakin tinggi komunikasi interpersonal dan fasilitas kesehatan yang diberikan akan menciptakan kecenderungan perilaku konsumen yang menguntungkan rumah sakit. Begitu pula sebaliknya, apabila pasien tidak mendapatkan komunikasi interpersonal dan fasilitas kesehatan yang baik maka akan menimbulkan kecenderungan perilaku pasien yang tidak menguntungkan sehingga akan merugikan rumah sakit (Zeithaml dan Bitner, 2001).

Berdasarkan uraian di atas, maka dapat dirumuskan hipotesis penelitian sebagai berikut:

H1: Diduga terdapat pengaruh yang signifikan antara variabel komunikasi interpersonal terhadap kepercayaan pada Rumah Sakit Umum Daerah Kota Mataram.

H2: Diduga terdapat pengaruh yang signifikan antara variabel fasilitas kesehatan terhadap kepercayaan pada Rumah Sakit Umum Daerah Kota Mataram.

\section{Hubungan Komunikasi Interpersonal dan Fasilitas Kesehatan dengan WOM}

Komunikasi interpersonal dan fasilitas kesehatan merupakan salah satu variabel yang dapat mempengaruhi WOM. Semakin baik komunikasi interpersonal dan fasilitas kesehatan yang diberikan oleh suatu rumah sakit akan dapat membentuk perilaku pasien untuk menciptakan WOM yang menguntungkan rumah sakit. Tapi apabila komunikasi interpersonal dan fasilitas kesehatan yang diberikan tidak memenuhi harapan pasien maka WOM tidak akan tercipta atau bahkan pasien akan melakukan WOM negatif.

WOM dewasa ini menjadi salah satu alternatif yang banyak diharapkan memberikan solusi dan langkah strategis bagi perusahaan dan banyak peneliti 
untuk dapat membantu meningkatkan derajat manajemen hubungan pelanggan. WOM merupakan kebijakan strategis bagi perusahaan, karena perusahaan memandang WOM merupakan bagian dari strategi perusahaan dalam menghadapi pesaing dan menghubungkan perusahaan dengan pasar (konsumen). WOM sangat dibutuhkan sebagai elemen dalam strategi pemasaran yang kompetitif. Dalam kondisi pasar yang makin kompetitif, perusahaan seringkali menyandarkan masa depan mereka pada pelanggan. Oleh karena itu, bagi sebagian perusahaan acap kali mengidentifikasikan WOM sebagai jaminan keuntungan jangka pendek dan jangka panjang bagi para perusahaan (Vandaliza, 2007).

Harrison dan Walker (2001) menyatakan bahwa komunikasi interpersonal dan fasilitas kesehatan merupakan salah satu variabel yang dapat mempengaruhi WOM. Penelitian ini menyatakan bahwa komunikasi interpersonal dan fasilitas kesehatan secara positif berpengaruh terhadap kecenderungan pasien untuk melakukan WOM. Persepsi komunikasi interpersonal dan fasilitas kesehatan yang lebih tinggi dari pada harapan pasien, akan menciptakan suatu WOM yang positif. Namun, jika komunikasi interpersonal dan fasilitas kesehatan yang ditawarkan lebih rendah daripada harapan pasien, maka pasien tersebut akan memberikan rekomendasi atau WOM negatif. Informasi negatif tersebut akan disebarkan kepada lebih banyak orang dengan tingkat intensitas yang tinggi dan secara detail, hal ini dikarenakan karena pada dasarnya seseorang tidak ingin orang lain mendapatkan atau mengalami hal buruk seperti pengalaman yang telah terjadi pada pasien tersebut.

Suatu rumah sakit dalam mempertimbangkan penerapan komunikasi interpersonal dan fasilitas kesehatan berhubungan dengan bagaimana rumah sakit tersebut memposisikan dirinya dalam memahami nilai dasar pasien (Gwinner et al., 1998). Selanjutnya Boulding et al (1993) sangat percaya bahwa komunikasi interpersonal dan fasilitas kesehatan berpengaruh secara positif terhadap WOM positif. Komunikasi interpersonal dan fasilitas kesehatan berhubungan dengan kepercayaan pasien dan komunikasi WOM yang positif (Zeithamal et al., 1996). Komunikasi interpersonal dan fasilitas kesehatan berpengaruh positif terhadap komunikasi WOM (Harrison dan Walker, 2001).Dengan demikian dapat diajukan hipotesis penelitian berikut ini:

H3: Diduga terdapat pengaruh yang signifikan antara variabel komunikasi interpersonal terhadap WOM pada Rumah Sakit Umum Daerah Kota Mataram.

H4: Diduga terdapat pengaruh yang signifikan antara variabel fasilitas kesehatan terhadap WOM pada Rumah Sakit Umum Daerah Kota Mataram.

\section{Hubungan Kepercayaan dengan WOM}

Kepercayaan pasien merupakan hal yang penting bagi penyedia jasa kesehatan, karena pasien akan menyebarluaskan rasa percayanya ke calon pasien, sehingga akan menaikkan reputasi rumah sakit tersebut. Jadi apabila pasien merasa percaya, maka ia akan menciptakan WOM kepada rekan maupun keluarganya. Brown et al (2005) menyatakan bahwa ketika seorang pemasar mampu menawarkan tingkat kepercayaan yang maksimal kepada konsumen, maka 
konsumen akan memiliki kecenderungan untuk melakukan positive word of mouth. Selain itu dia juga menyatakan bahwa terdapat pengaruh positif antara kepercayaan dan WOM.

Ketika konsumen percaya dan yakin, maka WOM positif akan tercipta dan mereka lebih suka untuk memberikan rekomendasi pembelian kepada orang lain (Swan dan Oliver, 1989). Dalam penelitian yang dilakukan oleh Wirts and Chew (2002) juga mendukung hasil tersebut yaitu kepercayaan secara signifikan berpengaruh terhadap WOM dan keinginan untuk melakukan rekomendasi pembelian. Ketika konsumen percaya maka mereka akan memberikan WOM positif dan merekomendasikan orang lain untuk melakukan pembelian. Sedangkan konsumen yang tidak percaya, mereka akan melarang orang lain untuk melakukan pembelian.

Kepercayaan pasien dapat mempengaruhi hasil kinerja, termasuk komunikasi WOM atau minat mereferensikan. Oleh sebab itu, kepercayaan pasien mendorong terciptanya komunikasi WOM (Thurau et al., 2003). Babin et al (2005) menyatakan bahwa kepercayaan pasien berpengaruh positif terhadap minat WOM. Kepercayaan pasien berhubungan kuat secara positif terhadap WOM (Ranaweera dan Prabhu, 2003; dan Brown et al., 2005). Berdasarkan uraian di atas, maka hipotesis 5 dapat diuraikan sebagai berikut:

H5: Diduga terdapat pengaruh yang signifikan antara variabel kepercayaan terhadap WOM pada Rumah Sakit Umum Daerah Kota Mataram.

\section{Hubungan Komunikasi Interpersonal dan Fasilitas Kesehatan dengan Kepercayaan dan WOM (Word of Mouth)}

Komunikasi interpersonal, fasilitas kesehatan, dan kepercayaan merupakan variabel yang dapat mempengaruhi WOM. Semakin baik komunikasi interpersonal, fasilitas kesehatan, dan kepercayaan yang diberikan oleh suatu rumah sakit akan dapat membentuk perilaku pasien untuk menciptakan WOM yang menguntungkan rumah sakit. Tapi apabila komunikasi interpersonal fasilitas kesehatan, dan kepercayaan yang diberikan tidak memenuhi harapan pasien maka pasien akan melakukan WOM negatif. Berdasarkan temuan dalam penelitian yang dilakukan oleh Alif dan Harahap (2013) diketahui bahwa komunikasi interpersonal dan fasilitas kesehatan berpengaruh positif dan signifikan terhadap kepercayaan. Hal ini berarti semakin baik komunikasi interpersonal dan fasilitas kesehatan yang diberikan, maka akan semakin baik pula kepercayaan pasien terhadap suatu layanan kesehatan. Dengan kepercayaan yang tinggi ini akan dapat dibangun WOM yang positif, dimana kepercayaan terbukti berpengaruh positif dan signifikan terhadap WOM. Dengan demikian dapat dinyatakan bahwa komunikasi interpersonal dan fasilitas kesehatan dapat mempengaruhi WOM melalui kepercayaan. Hipotesis selanjutnya yang dapat diajukan dalam penelitian ini adalah:

H6: Diduga terdapat pengaruh yang signifikan antara variabel komunikasi interpersonal melalui kepercayaan terhadap WOM pada Rumah Sakit Umum Daerah Kota Mataram. 


\begin{tabular}{|c|c|}
\hline JMM & $\begin{array}{c}\text { JURNAL MAGISTER MANAJEMEN } \\
\text { UNIVERSITAS MATARAM } \\
\text { Maret } 2015\end{array}$ \\
\hline
\end{tabular}

H7: Diduga terdapat pengaruh yang signifikan antara variabel fasilitas kesehatan melalui kepercayaan terhadap WOM pada Rumah Sakit Umum Daerah Kota Mataram.

Untuk memudahkan pemahaman mengenai konsep dasar dan alur pikir dalam penelitian ini, maka disusun kerangka konseptual, sebagai berikut:

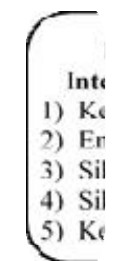

$$
\mid
$$
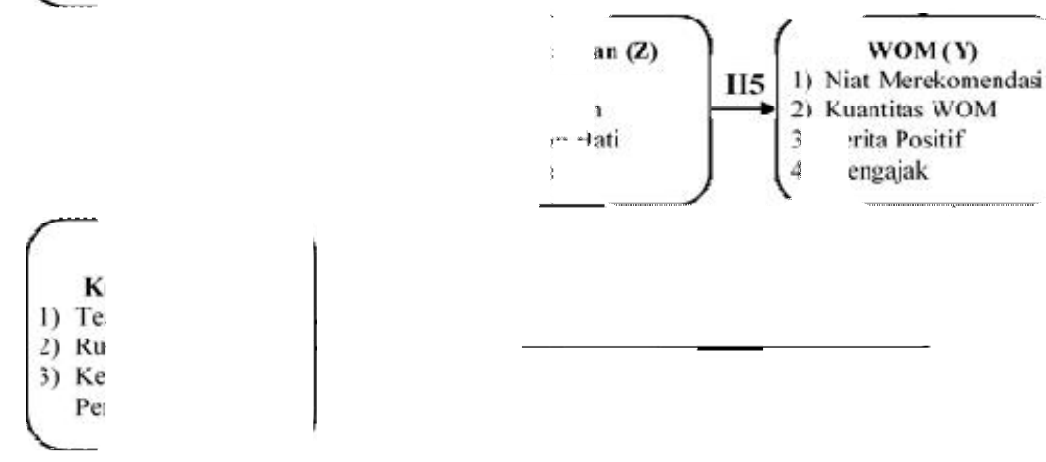

$$
\mid
$$

\section{Gambar Kerangka Konseptual Penelitian}

\section{Metode Penelitian}

Pada penelitian ini, peneliti akan menggunakan jenis penelitian asosiatif yang dijelaskan melalui pendekatan penelitian kuantitatif, yang tujuan utamanya adalah mendapatkan bukti mengenai hubungan sebab akibat. Penelitian asosiatif merupakan penelitian yang melakukan analisis hubungan atau pengaruh dari satu atau lebih variabel lainnya (Sugiyono, 2008).

Sampel menurut Malhotra (2009) "sampel adalah sub kelompok elemen populasi yang terpilih untuk berpartisipasi dalam studi". Mengingat jumlah populasi yang tidak diketahui, maka teknik pengambilan sampel dalam penelitian ini adalah dengan 


\section{$J M M$ UNRAM

menggunakan teknikpurposive sampling atau pemilihan sampel tertentu/kriteria yang bertujuan lebih spesifik lagi termasuk kategori sampel berdasarkan pertimbangan. Adapun kriteria yang ditentukan dalam penelitian ini yaitu pasien umum yang menjalani rawat jalan di poli pada RSUD Kota Mataram dan pasien sudah berobat lebih dari dua kali. Kriteria ini diterapkan agar responden dalam penelitian mampu menjadi representasi dari populasi pasien yang berobat jalan di RSUD Kota Mataram yang mengetahui seluk-beluk layanan kesehatan, sehingga lebih dapat memahami kelebihan dan kekurangan dari layanan kesehatan yang digunakan.

Besarnya jumlah sampel yang diambil untuk penelitian ini adalah 115 orang responden, dimana dalam penelitian ini terdapat 23 indikator yang diukur menggunakan skala likert 5 tingkat. Jumlah ini didasarkan pada pendapat Roscoe dalam Sekaran (2006) yang mengatakan bahwa ukuran sampel untuk setiap penelitian harus berada di antara 30 dan 500, sehingga jumlah ini lebih besar dari 30 orang dan sudah dianggap bisa mewakili jumlah populasi.

Teknik analisis data yang digunakan adalah path analysis/analisis jalur. Analisis jalur digunakan untuk melukiskan dan menguji model hubungan antara variabel yang berbentuk sebab-akibat (Sugiyono, 2008). Jadi model path analysis digunakan untuk menganalisis hubungan antara variabel dengan tujuan untuk mengetahui pengaruh langsung atau tidak langsung seperangkat variabel bebas terhadap variabel terikat (Kuncoro, 2007:2).Path Analysis dalam menguji besarnya sumbangan (kontribusi) yang ditunjukan oleh koefisien jalur pada setiap diagram jalur dari hubungan kausal antar variabel.

\section{Analisis Data dan Pembahasan}

Hasil Uji Kualitas Instrumen Penelitian

Berdasarkan hasil pengujian validitas untuk item kuesioner penelitian terkait variabel komunikasi interpersonal, fasilitas kesehatan, kepercayaan, dan word of mouth secara keseluruhan adalah valid. Hal ini diketahui dengan melihat perbandingan antara nilai $r$ hitung dengan $\mathrm{r}$ tabel, dimana nilai $\mathrm{r}$ hitung yang dihasilkan lebih besar dari $\mathrm{r}$ tabel. Selanjutnya untuk menentukan hasil dari uji reliabilitas dalam penelitian ini, dilihat dari hasil Cronbach Alpha. Untuk keseluruhan hasil uji reliabilitas variabel komunikasi interpersonal, fasilitas kesehatan, kepercayaan, dan word of mouth ditentukan melalui tabel Reliability Statistics. Untuk hasil uji reliabilitas, dari hasilkeseluruhan item yang diujikan dalam penelitian ini, terlihat bahwa hasilreliabilitasnyaadalah lebih besar dari syarat minimal sebesar 0,600 yang berarti seluruh variabel dalam penelitian ini dinyatakan reliabel.

Uji HipotesisPengaruh Komunikasi Interpersonal (X1) dan Fasilitas Kesehatan (X2) terhadap Kepercayaan (Z)

Besarnya angka R Square $\left(\mathrm{r}^{2}\right)$ adalah 0,944 , angka tersebut dapat digunakan untuk dapat melihat besarnya kontribusi komunikasi interpersonal dan fasilitas kesehatan dalam menjelaskan kepercayaan, dengan cara menghitung koefisien determinasi $(\mathrm{KD})$ dengan menggunakan rumus $\mathrm{KD}=\mathrm{r}^{2} \mathrm{X} 100 \%=0,944 \times 100 \%=$ 94,40\%. Angka tersebut mempunyai maksud bahwa komunikasi interpersonal dan 
fasilitas kesehatan mampu menjelaskan kepercayaan sebesar94,40 persen. Adapun sisanya 5,60 persen $(100 \%-94,40 \%)$ dijelaskan oleh faktor lain. Dengan kata lain, variabel kepercayaan yang dapat diterangkan dengan menggunakan variabel komunikasi interpersonal dan fasilitas kesehatan sebesar 94,40 persen, sedangkan sisanya sebesar 5,60 persen dibentuk oleh variabel-variabel lain di luar model ini.Analisis path dapat pula disajikan dalam bentuk persamaan sebagai berikut:

$$
\begin{aligned}
& z=\rho_{z x 1} X_{1}+\rho_{z x 2} X_{2}+\varepsilon 1 \\
& z=0,207 X_{1}+0,780 X_{2}+0,170 \varepsilon 1
\end{aligned}
$$

a) Nilai koefisien regresi variabel komunikasi interpersonal $\left(X_{1}\right)$, adalah sebesar 0,207. Artinya jika komunikasi interpersonal $\left(X_{1}\right)$ berubah satu satuan, maka kepercayaan $(Z)$ akan berubah sebesar 0,207 dengan asumsi variabel lainnya tetap. Koefisien regresi yang bertanda positif menunjukkan pengaruh yang searah antara komunikasi interpersonal $\left(X_{1}\right)$ dengan kepercayaan $(Z)$. Artinya apabila komunikasi interpersonal $\left(X_{1}\right)$ meningkat maka kepercayaan $(Z)$ akan meningkat dan sebaliknya.

b) Nilai koefisien regresi variabel fasilitas kesehatan $\left(X_{2}\right)$, adalah sebesar 0,780. Artinya jika fasilitas kesehatan $\left(X_{2}\right)$ berubah satu satuan, maka kepercayaan $(Z)$ akan berubah sebesar 0,780 dengan asumsi variabel lainnya tetap. Koefisien regresi yang bertanda positif menunjukkan pengaruh yang searah antara fasilitas kesehatan $\left(X_{2}\right)$ dengan kepercayaan $(\mathrm{Z})$. Artinya apabila fasilitas kesehatan $\left(\mathrm{X}_{2}\right)$ meningkat maka kepercayaan (Z) akan meningkat dan sebaliknya.

Berdasarkan analisis data diperoleh nilai $\mathrm{F}$ hitung sebesar 938,120. Kemudian dengan menggunakan tingkat keyakinan 95 persen, df1 $(n-1)=2$, dan df2 $(n-k)=$ $115-3=112$, sehingga diperoleh hasil untuk $\mathrm{F}$ tabel sebesar 3,080. Karena nilai $\mathrm{F}$ hitung lebih besar dari $\mathrm{F}$ tabel $(938,120>3,080)$ maka dapat disimpulkan bahwa terdapat pengaruh yang signifikan antara komunikasi interpersonal dan fasilitas kesehatan terhadap kepercayaanpasien RSUD Kota Mataram.

Untuk melihat bagaimana pengaruh antara komunikasi interpersonal terhadap kepercayaan pada pasien RSUD Kota Mataram digunakan uji t. Dapat dilihat bahwa nilai $t$ hitung positif untuk variabel komunikasi interpersonal sebesar 3,926. Untuk menemukan jawaban atas hipotesis yang ada maka perlu dibandingkan antara $t$ hitung dengan $t$ tabel.Dengan menggunakan tingkat keyakinan 95 persen df (degree of freedom) $n-1=115-1=114$, sehingga diperoleh hasil untuk $t$ tabel sebesar 1,981. Karena $t$ hitung komunikasi interpersonal lebih besar dari $t$ tabel $(3,926>1,981)$, maka dapat disimpulkan bahwa terdapat pengaruh yang signifikan dari komunikasi interpersonal terhadap kepercayaan pasien pada RSUD Kota Mataram. Selain itu dapat dilihat pada Tabel 4.12. dimana nilai signifikansi yang diperoleh adalah 0,000 . Nilai probabilitas signifikansi tersebut lebih kecil dari probabilitas $0,050(0,000<0,050)$, artinya bahwa koefisien jalur tersebut adalah signifikan. Nilai signifikansi ini semakin mempertegas pengaruh signifikan antara komunikasi interpersonal terhadap kepercayaan. Dengan demikian Hipotesis 1 yang diajukan dalam penelitian ini dapat diterima. 
Mengenai pengaruh antara fasilitas kesehatan terhadap kepercayaan pada pasien RSUD Kota Mataramjuga menggunakan uji t. Dapat dilihat bahwa nilai $t$ hitung positif untuk variabel fasilitas kesehatan sebesar 14,808. Untuk menemukan jawaban atas hipotesis yang ada maka perlu dibandingkan antara $t$ hitung dengan $t$ tabel.Karena nilai t hitung fasilitas kesehatan lebih besar dari t tabel $(14,808>1,981)$, maka dapat disimpulkan bahwa terdapat pengaruh yang signifikan dari fasilitas kesehatan terhadap kepercayaan pasien pada RSUD Kota Mataram.Selanjutnya nilai probabilitas signifikansi untuk variabel fasilitas kesehatan juga lebih kecil dari nilai probabilitas $0,050(0,000<0,050)$, artinya bahwa koefisien jalur dalam penelitian ini adalah signifikan. Jadi ada pengaruh yang signifikan antara fasilitas kesehatan terhadap kepercayaan.Dengan demikian Hipotesis 2 yang menyatakan terdapat pengaruh yang signifikan antara fasilitas kesehatan terhadap kepercayaan yang diajukan dalam penelitian ini dapat diterima.

Pengaruh Komunikasi Interpersonal (X1) dan Fasilitas Kesehatan (X2) melalui Kepercayaan (Z) terhadap Word of Mouth (Y)

Besarnya angka $\mathrm{R}$ Square $\left(\mathrm{r}^{2}\right)$ adalah 0,587 , angka tersebut dapat digunakan untuk dapat melihat besarnya kontribusi komunikasi interpersonal, fasilitas kesehatan dan kepercayaan dalam membentukword of mouth, dengan cara menghitung koefisien determinasi (KD) menggunakan rumus $\mathrm{KD}=\mathrm{r}^{2} \mathrm{X} 100 \%=$ $0,587 \times 100 \%=58,70 \%$. Angka tersebut mempunyai maksud bahwa kontribusi komunikasi interpersonal, fasilitas kesehatan dan kepercayaan dalam menjelaskan word of mouth adalah sebesar 58,70 persen, adapun sisanya 41,30 persen $(100 \%-$ $58,70 \%)$ dijelaskan oleh faktor lain di luar model. Dengan kata lain, variabel word of mouth yang dapat diterangkan dengan menggunakan variabel komunikasi interpersonal dan fasilitas kesehatan melalui kepercayaan sebesar 58,70 persen, sedangkan sebesar 41,30 persen disebabkan oleh variabel-variabel lain diluar model penelitian ini.Analisis path dapat pula disajikan dalam bentuk persamaan sebagai berikut:

$$
\begin{aligned}
& Y=\rho_{y x 1} X_{1}+\rho_{y x 2} X_{2}+\rho_{y z} Z+\varepsilon 2 \\
& Y=1,251 X_{1}+0,248 X_{2}+0,826 Z+0,484 \varepsilon 2
\end{aligned}
$$

Hasil perhitungan regresi pada Tabel 4.13. dapat dijelaskan sebagai berikut:

a) Nilai koefisien regresi variabel komunikasi interpersonal $\left(X_{1}\right)$, adalah sebesar 1,251. Artinya jika komunikasi interpersonal $\left(\mathrm{X}_{1}\right)$ berubah satu satuan, maka word of mouth $(\mathrm{Y})$ akan berubah sebesar 1,251 dengan asumsi variabel lainnya tetap. Koefisien regresi yang bertanda positif menunjukkan pengaruh yang searah antara komunikasi interpersonal $\left(\mathrm{X}_{1}\right)$ dengan word of mouth $(\mathrm{Y})$. Artinya apabila komunikasi interpersonal $\left(\mathrm{X}_{1}\right)$ meningkat maka word of mouth (Y) akan meningkat dan sebaliknya.

b) Nilai koefisien regresi variabel fasilitas kesehatan $\left(X_{2}\right)$, adalah sebesar 0,248 . Artinya jika fasilitas kesehatan $\left(\mathrm{X}_{2}\right)$ berubah satu satuan, maka word of mouth $(\mathrm{Y})$ akan berubah sebesar 0,248 dengan asumsi variabel lainnya tetap. Koefisien regresi yang bertanda positif menunjukkan pengaruh yang searah antara fasilitas kesehatan $\left(\mathrm{X}_{2}\right)$ dengan word 
of mouth $(\mathrm{Y})$. Artinya apabila fasilitas kesehatan $\left(\mathrm{X}_{2}\right)$ meningkat maka word of mouth $(\mathrm{Y})$ akan meningkat dan sebaliknya.

c) Nilai koefisien regresi variabel kepercayaan (Z), adalah sebesar 0,826. Artinya jika kepercayaan (Z)berubah satu satuan, maka word of mouth $(\mathrm{Y})$ akan berubah sebesar 0,826 dengan asumsi variabel lainnya tetap. Koefisien regresi yang bertanda positif menunjukkan pengaruh yang searah antara kepercayaan $(Z)$ dengan word of mouth $(Y)$. Artinya apabila kepercayaan $(\mathrm{Z})$ meningkat maka word of mouth $(\mathrm{Y})$ akan meningkat dan sebaliknya.

Berdasarkan analisis regresi linier berganda diperoleh nilai $\mathrm{F}$ hitung sebesar 52,682. Kemudian dengan menggunakan tingkat keyakinan 95 persen, df1 $(\mathrm{k}-1)=$ 3 , dan df2 $(\mathrm{n}-\mathrm{k})=115-4=111$, sehingga diperoleh hasil untuk $\mathrm{F}$ tabel sebesar 2,690 . Oleh karena F hitung lebih besar dari F tabel $(52,682>2,690)$ maka dapat disimpulkan bahwa terdapat pengaruh yang signifikan antara komunikasi interpersonal dan fasilitas kesehatan melalui kepercayaan terhadap word of mouthRSUD Kota Mataram.

Untuk melihat bagaimana pengaruh antara komunikasi interpersonal dan fasilitas kesehatan melalui kepercayaan terhadap word of mouth pada RSUD Kota Mataram digunakan uji t. Dapat dilihat bahwa nilai t hitung positif untuk variabel komunikasi interpersonal sebesar 8,191. Untuk menemukan jawaban atas hipotesis yang ada maka perlu dibandingkan antara $t$ hitung dengan $t$ tabel.Dengan menggunakan tingkat keyakinan 95 persen, maka pada degree of freedom $n-1=115$ $1=114$, diperoleh hasil untuk $\mathrm{t}$ tabel sebesar 1,981. Karena $\mathrm{t}$ hitung komunikasi interpersonal lebih besar dari t tabel $(8,191>1,981)$, maka dapat disimpulkan bahwa terdapat pengaruh yang signifikan dari komunikasi interpersonal terhadap word of mouth. Selanjutnya nilai signifikansi untuk variabel komunikasi interpersonal adalah 0,000 . Nilai probabilitas signifikansi tersebut lebih kecil dari probabilitas $0,050(0,000<0,050)$, artinya bahwa koefisien jalur tersebut signifikan. Jadi nilai probabilitas signifikansi ini semakin memperkuat bukti bahwa terdapat pengaruh yang signifikan antara komunikasi interpersonal terhadap word of mouth. Dengan demikian Hipotesis 3 yang menyatakan terdapat pengaruh yang signifikan antara komunikasi interpersonal terhadapword of mouth dapat diterima.

Pengaruh antara fasilitas kesehatan terhadap word of mouth pada RSUD Kota Mataram diperoleh nilai $\mathrm{t}$ hitung positif sebesar 1,007. Untuk menemukan jawaban atas hipotesis yang menyatakan terdapat pengaruh yang signifikan antara fasilitas kesehatan terhadap word of mouth pada RSUD Kota Mataram maka perlu dibandingkan antara $t$ hitung dengan $t$ tabel.Karena $t$ hitung fasilitas kesehatanlebih kecil dari $\mathrm{t}$ tabel $(1,007<1,981)$, maka dapat dinyatakan bahwa tidak terdapat pengaruh yang signifikan antara fasilitas kesehatan terhadap word of mouth. Selain itu dapat dilihat juga nilai signifikansi untuk variabel fasilitas kesehatan diperoleh nilai sebesar 0,316. Nilai probabilitas signifikansi tersebut lebih besar dari probabilitas $0,050(0,316>0,050)$, artinya bahwa koefisien jalur tersebut tidak signifikan. Jadi nilai probabilitas signifikansi ini menyatakan bahwa Hipotesis 4 yang diajukan dalam penelitian ini ditolak atau tidak diterima, sebab analisis data 
membuktikan bahwa tidak terdapat pengaruh yang signifikan antara fasilitas kesehatan terhadapword of mouthpada RSUD Kota Mataram.

Berdasarkan informasi output regresi linier berganda diperoleh nilai $t$ hitung positif untuk variabel kepercayaan sebesar 3,217. Karena t hitung kepercayaan lebih besar dari t tabel $(3,217>1,981)$, maka dapat disimpulkan bahwa terdapat pengaruh yang signifikan antara kepercayaan terhadap word of mouth. Selanjutnya nilai signifikansi untuk variabel kepercayaan sebesar 0,002. Nilai probabilitas signifikansi tersebut lebih kecil dari nilai probabilitas 0,050 . Hal ini menyatakan bahwa koefisien jalur tersebut signifikan, nilai probabilitas signifikansi ini semakin memperkuat bukti bahwa terdapat pengaruh yang signifikan antara kepercayaan terhadap word of mouth. Dengan demikian Hipotesis 5 yang diajukan dalam penelitian ini dapat diterima.

\section{Menghitung Pengaruh Tidak Langsung (Indirect Effect)}

Besarnya pengaruh tidak langsung variabel komunikasi interpersonal terhadap word of mouth melalui kepercayaan diperoleh melalui hasil perkalian koefisien jalur (beta) antara pengaruh langsung komunikasi interpersonal terhadap kepercayaan dengan pengaruh langsung kepercayaan terhadap word of mouth. Untuk pengaruh tidak langsung antara variabel fasilitas kesehatan terhadap word of mouth melalui kepercayaan diperoleh melalui hasil perkalian koefisien jalur (beta) antara pengaruh langsung fasilitas kesehatan terhadap kepercayaan dengan pengaruh langsung kepercayaan terhadap word of mouth. Besarnya pengaruh tidak langsung komunikasi interpersonal dan fasilitas kesehatan memberikan pengaruh tidak langsung terhadap word of mouth melalui kepercayaanmasing-masing sebesar 0,171 dan 0,644 .

\section{Pengaruh Total (Total Effect)}

Besarnya pengaruh total merupakan penjumlahan dari pengaruh langsung dan tidak langsung dari seluruh jalur setiap variabel dalam penelitian ini. Perhitungan pengaruh total akan diperlihatkan pada Tabel 1. Untuk lebih jelasnya pada tabel tersebut juga ditampilkan terlebih dahulu rangkuman perhitungan pengaruh langsung dan pengaruh tidak langsung yang telah diuraikan sebelumnya dan selanjutnya diteruskan dengan perhitungan pengaruh total variabel penelitian.

Tabel Perhitungan Pengaruh Total Komunikasi Interpersonal dan Fasilitas Kesehatan melalui Kepercayaan terhadap Word of Mouth

\begin{tabular}{lllcc}
\hline \multicolumn{1}{c}{ Pengaruh Variabel } & Simbol & $\begin{array}{c}\text { Gambaran } \\
\text { Jalur }\end{array}$ & $\begin{array}{c}\text { Formula } \\
\text { Perhitunga } \\
\text { n }\end{array}$ & Hasil \\
\hline $\begin{array}{c}\text { Komunikasi Interpersonal terhadap } \\
\text { Kepercayaan(H1) }\end{array}$ & $\mathrm{TEZX}_{1}$ & $\mathrm{X}_{1} \rightarrow \mathrm{Z}$ & 0,207 & 0,207 \\
$\begin{array}{c}\text { Fasilitas Kesehatan terhadap } \\
\text { Kepercayaan(H2) }\end{array}$ & $\mathrm{TEZX}_{2}$ & $\mathrm{X}_{2} \rightarrow \mathrm{Z}$ & 0,780 & 0,780 \\
$\begin{array}{l}\text { Komunikasi Interpersonal terhadap } \\
\quad \text { Word of Mouth(H3) }\end{array}$ & $\mathrm{TEYX}_{1}$ & $\mathrm{X}_{1} \rightarrow \mathrm{Y}$ & 1,251 & 1,251 \\
$\begin{array}{l}\text { Fasilitas Kesehatan terhadap Word of } \\
\text { Mouth(H4) }\end{array}$ & $\mathrm{TEYX}_{2}$ & $\mathrm{X}_{2} \rightarrow \mathrm{Y}$ & 0,248 & 0,248 \\
Kepercayaan terhadap Word of & $\mathrm{TEYZ}$ & $\mathrm{Z} \rightarrow \mathrm{Y}$ & 0,826 & 0,826 \\
\hline
\end{tabular}




\section{TMM JURNAL MAGISTER MANAJEMEN UNIVERSITAS MATARAM \\ Maret 2015}

\begin{tabular}{|c|c|c|c|c|}
\hline $\operatorname{Mouth}(\mathrm{H} 5)$ & & & & \\
\hline $\begin{array}{l}\text { Komunikasi Interpersonal melalui } \\
\text { Kepercayaan terhadap Word of } \\
\text { Mouth }(\mathrm{H} 6)\end{array}$ & TEYZX $_{1}$ & $\mathrm{X}_{1} \rightarrow \mathrm{Z} \rightarrow \mathrm{Y}$ & $(0,207+0,826)$ & 1,033 \\
\hline $\begin{array}{l}\text { Fasilitas Kesehatan melalui } \\
\text { Kepercayaan terhadap Word of } \\
\text { Mouth }(\mathrm{H} 7)\end{array}$ & TEYZX $_{2}$ & $\mathrm{X}_{2} \rightarrow \mathrm{Z} \rightarrow \mathrm{Y}$ & $(0,780+0,826)$ & 1,606 \\
\hline
\end{tabular}

Sumber: Data Primer Diolah.

Berdasarkan hasil perhitungan tabel diatas maka dapat dijelaskan bahwa pengaruh komunikasi interpersonal terhadap kepercayaan sebesar $\left(0,207^{2} \mathrm{x}\right.$ $100 \%) 4,28$ persen. Pengaruh fasilitas kesehatan terhadap kepercayaan $\left(0,780^{2} \times\right.$ $100 \%$ )60,84 persen. Pengaruh komunikasi interpersonal terhadap word of mouth $\left(1,251^{2} \times 100 \%\right) 156,50$ persen. Pengaruh fasilitas kesehatan terhadap word of mouth $\left(0,248^{2} \times 100 \%\right) 6,15$ persen. Pengaruh kepercayaan terhadap word of mouth $\left(0,826^{2} \times 100 \%\right) 68,23$ persen. Pengaruh komunikasi interpersonal terhadap word of mouth melalui kepercayaan $\left(1,033^{2} \times 100 \%\right) 106,71$ persen.Pengaruh fasilitas kesehatan terhadap word of mouth melalui kepercayaan $\left(1,606^{2} \times 100 \%\right) 257,92$ persen.

Pengaruh variabel komunikasi interpersonal terhadap word of mouth melalui kepercayaan diketahui nilai koefisien jalur yang positif. Selanjutnya nilai probabilitas signifikansi untuk pengaruh tersebut lebih kecil dari nilai probabilitas 5 persen. Maka dapat disimpulkan bahwa terdapat pengaruh yang signifikan antara kepercayaan terhadap word of mouthmelalui kepercayaan.Hal ini menyatakan bahwa koefisien jalur tersebut signifikan, nilai probabilitas signifikansi ini semakin memperkuat bukti bahwa terdapat pengaruh yang signifikan antara komunikasi interpersonal terhadap word of mouthmelalui kepercayaan. Dengan demikian Hipotesis 6 yang diajukan dalam penelitian ini dapat diterima.

Untuk variabel fasilitas kesehatan terhadap word of mouth melalui kepercayaan diperolehnilai koefisien jalur yang positif dengan nilai probabilitas signifikansi yang lebih kecil dari 5 persen. Hal ini menyatakan bahwa koefisien jalur pengaruh yang signifikan antara komunikasi interpersonal terhadap word of mouthmelalui kepercayaan, atau dengan kata lain menerima $\mathrm{H}_{\mathrm{a}}$ dan menolak $\mathrm{H}_{0}$, sehingga Hipotesis 7 yang diajukan dalam penelitian ini dapat diterima.

\section{Pengujian Model}

Pengujian model dalam penelitian ini menggunakan model trimming. Ridwan dan Kuncoro (2007) mengatakan bahwa model trimming adalah model yang digunakan untuk memperbaiki suatu model struktur analisis jalur dengan cara mengeluarkan dari model variabel eksogen yang koefisien jalurnya tidak signifikan. Jadi model terjadi ketika koefisien jalur diuji secara keseluruhan ternyata ada variabel yang tidak signifikan. Maka peneliti perlu memperbaiki model struktur analisis jalur yang dihipotesiskan.Cara menggunakan model trimming adalah menghitung ulang koefisien jalur tanpa menyertakan variabel eksogen yang koefisien jalurnya tidak signifikan. Berdasarkan model analisis jalur diketahui semua koefisienjalur dinyatakan signifikan sebagaimana dijelaskan pada analisis sebelumnya, hanya fasilitas kesehatan yang tidak berpengaruh signifikan terhadap 
word of mouth. Dengan demikian perlu diadakan penghitungan ulang, sehingga model yang dihasilkan seperti pada gambar berikut ini:

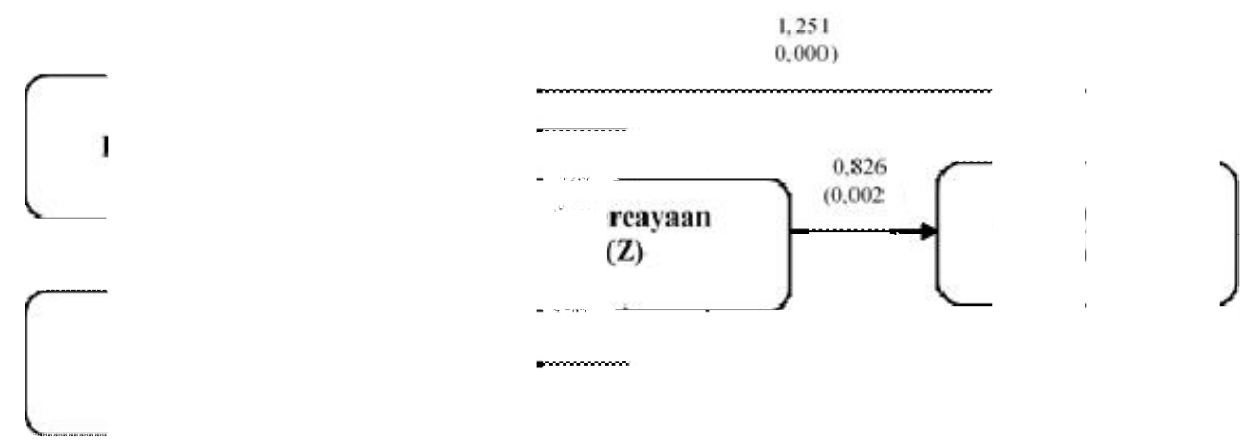

\section{Gambar Model Analisis Jalur Setelah Trimming}

Berdasarkan pada Gambar di atas diketahui bahwa setiap variabel pembentuk model penelitian menunjukkan hasil yang memenuhi kriteria nilai signifikansi koefisien jalur lebih kecil dari 5 persen. Hasil tersebut dapat dikatakan bahwa secara keseluruhan model penelitian setelah trimming yang diajukan dalam penelitian ini dapat diterima.

\section{Kesimpulan dan Rekomendasi}

Berdasarkan hasil penelitian dan pembahasan yang telah dilakukan mengenai pengaruh komunikasi interpersonaldan fasilitas kesehatan melalui kepercayaan terhadap word of mouth pada pasien RSUD Kota Mataram dapat diambil beberapa kesimpulan sebagai berikut:

a) Komunikasi interpersonalmempunyai pengaruh positif dan signifikan terhadap kepercayaan.

b) Fasilitas kesehatan mempunyai pengaruh positif dan signifikan terhadap kepercayaan.

c) Komunikasi interpersonal mempunyai pengaruh positif dan signifikan terhadap word of mouth.

d) Kepercayaan mempunyai pengaruh positif dan signifikan terhadap word of mouthpasien.

e) Komunikasi interpersonal mempunyai pengaruh positif dan signifikan terhadap word of mouthmelalui kepercayaan.

f) Fasilitas kesehatan mempunyai pengaruh positif dan signifikan terhadap word of mouthmelalui kepercayaan.

Komunikasi interpersonal berpengaruh signifikan terhadap kepercayaan. Hal ini disebabkan oleh karena pasien memiliki ekspektasi yang lebih besar terhadap petugas medis (dokter dan perawat), dimana dalam penelitian ini komunikasi interpersonal memang terbukti mempengaruhi kepercayaan. Dengan demikian hal ini menegaskan kembali bahwa pasien datang untuk berobat di rumah sakit lebih karena mereka memiliki kepercayaan terhadap petugas medis di rumah sakit. 
Dengan demikian menjadi sangat penting bagi dokter dan perawat di rumah sakit untuk terus meningkatkan kemampuan komunikasi interpersonal mereka.

Fasilitas kesehatan terbukti berpengaruh signifikan terhadap kepercayaan. Hal ini disebabkan oleh karena pasien memiliki harapan yang besar terhadap fasilitas kesehatan yang tersedia di rumah sakit. Pasien datang untuk berobat di rumah sakit lebih karena mereka memiliki kepercayaan terhadap fasilitas kesehatan yang tersedia di rumah sakit. Penelitian ini memperlihatkan bahwa fasilitas kesehatan rumah sakit merupakan hal yang sangat penting untuk diperhatikan. Kelengkapan fasilitas kesehatan akan ikut memperbaiki kepercayaan pasien terhadap kualitas layanan kesehatan yang diberikan oleh rumah sakit.

Penelitian ini juga menegaskan kembali bahwa kepercayaan juga terbukti dapat membangkitkan word of mouth positif. Hal ini menjelaskan bahwa kepercayaan merupakan hal yang sangat penting dalam suatu aktifitas bisnis dan pemasaran, oleh karena itu disarankan kepada pihak manajemen RSUD Kota Mataram agar tetap mengelola kepercayaan yang telah diberikan pasien selama ini dengan sebaik mungkin.

\section{Daftar Pustaka}

Alif, M.G. (2013). Komunikasi Interpersonal dan Fasilitas Kesehatan: Pengaruhnya Terhadap Kepercayaan, Loyalitas dan WOM Rumah Sakit: Journal of Business and Entrepreneuship, Vol. 1, No.3; Oktober 2013.

Bendapudi, N., dan L.L. Berry. (1997). Customers I Motivation for Maintaining Relationships with Service Providers; Journal of Reatailing, 73 (1), 15-37.

Brown, B., dan D. Gunst. (2005). Spreading The Word: Investigating Antecedents of Consumers Positive Word of Mouth Intentions and Behaviors in a retailing Context, Journal the Academy of MarketingScience; Vol. 33. No. 2. pg. 123-138.

Djojodibroto, R. (2001). Kiat Mengelola Rumah Sakit. Jakarta: Penerbit Hipokrates

Morgan, R.M. dan S.D. Hunt (1994). The Commitment-Trust Theory Of Relationship Marketing; Journal of Marketing, 58 (July).

Malhotra, N.K. (2009). Marketing Research an Applied Orientation. Prentice Hall, New Jersey.

Sekaran, U., (2006). Metode Penelitian Bisnis. Salemba Empat, Jakarta.

Sugiyono, (2008). Metode Penelitian Kuantitatif, Kualitatif, dan R \& D. Alfabeta, Bandung.

Parasuraman, A., Zeithaml, V.A., dan Berry, L.B. (1985). A Conceptual Model of Service Quality and Its Implications for Further Research. Journal of Marketing, Vol.49, pp.41-50.

Zeithaml, V.A. dan Bitner, M.J. (2001). Service Marketing: Integrated Costumer Focus Across The Firm. McGraw-Hill Companies, New York. 